\title{
Strategies for Studying Opioid Peptide Regulation at the Gene, Message and Protein Levels
}

\author{
ROBERT M. DORES, HUDA AKIL AND STANLEY J. WATSON
}

Mental Health Research Institute. University of Michigan, Ann Arbor, MI 48109

\begin{abstract}
DORES. R. M., H. AKIL AND S. J. WATSON. Strategies for studying opioid peptide regulation at the gene, message and protein levels. PEPTIDES 5: Suppl 1, 9-17, 1984.- Three opioid peptide precursors have been isolated and characterized in endocrine and nervous tissue: pro-opiomelanocortin, pro-enkephalin, and pro-dynorphin. Since each of those opioid peptide systems have been extensively characterized both biochemically and anatomically, this review will focus on strategies for studying the regulation of these systems at the levels of gene transcription, message translation, posttranslational processing, secretion, and target cell receptor interaction.
\end{abstract}

Opioid peptides Transcription Translational Post-translational processing Secretion

THE endorphins consist of a collection of three biochemically discrete families of opioid peptides which are present as distinct systems in the pituitary as well as the central and peripheral nervous systems. As a result of the combined use of various immunological, biochemical, and molecular technologies, the end products of these systems have been fully characterized and the structure of the specific mRNAs, and in some cases the genes which code for these end products, have also been characterized. These topics have been reviewed extensively $[4,41,43]$, however, based on this information it is now possible to outline strategies to investigate the regulatory biology of opioid peptide systems in pituitary and nervous tissue. This review will focus on current approaches for understanding the regulation of these systems.

\section{THE OPIOID PEPTIDE FAMILIES}

At present three distinct precursors have been isolated in mammalian endocrine and nervous tissue which contain opioid peptides (Fig. 1): pro-opiomelanocortin, the precursor for $\beta$-endorphin-, ACTH- and $\gamma$-MSH-related end products [44]; pro-enkephalin, the precursor for methionineenkephalin-related end products and leucine-enkephalin [45]; pro-dynorphin, the precursor for dynorphin- and $\alpha$-neo-endorphin-related end products [26]. In addition to containing at least one copy of the opioid core peptide sequence Tyr-Gly-Gly-Phe(Leu, Met), these precursors share a number of properties in common. All three precursors are similar in size. For example bovine POMC [44] is 264 amino acids in size while human pro-enkephalin [45] and porcine pro-dynorphin [26] are, respectively, 267 and 256 amino acids in size. All three precursors code for multiple end products with cleavage usually, but not exclusively, occurring at pairs of basic residues. Finally, the $\mathrm{NH}_{2}$-terminal re- gion of all three precursors is an area rich in cysteine residues. In the case of pro-enkephalin and pro-dynorphin the placement and number of cysteine residues is nearly identical. Collectively these properties underscore the biochemical similarities of the three opioid precursor systems and raise the possibility that these proteins may have evolved from closely allied precursors.

\section{THE PRO-OPIOMELANOCORTIN SYSTEM}

End products of the pro-opiomelanocortin (POMC) system are synthesized in corticotropic cells of the anterior pituitary, melanotropic cells of the intermediate pituitary $[11,18]$, distinct neurons in the arcuate nucleus [2], and a subset of neurons in the nucleus tractus solitarius [31]. The network of POMC neurons in the brain is depicted in Fig. 2. Post-translational processing of POMC has been most thoroughly studied in the pituitary of mammals. In the anterior pituitary POMC is initially cleaved to yield $\beta$-lipotropin $(\beta$ $\mathrm{LPH}$; the COOH-terminal third of POMC) and ACTH biosynthetic intermediate (the $\mathrm{NH}_{2}$-terminal two thirds of POMC). The latter form is further cleaved to yield adrenocorticotropin (ACTH) and $16 \mathrm{~K}$ fragment (the $\gamma$ MSH-containing $\mathrm{NH}_{2}$-terminal third of POMC) as end products, while approximately one third of the $\beta$-LPH is further cleaved to yield $\gamma$ - LPH (the $\mathrm{NH}_{2}$-terminal two thirds of $\beta$-LPH) and opiate active $\beta$-endorphin (the COOH-terminal 31 residues of $\beta$-LPH) [18]. By contrast in the intermediate pituitary, $16 \mathrm{~K}$ fragment, ACTH and $\beta$-LPH serve as biosynthetic intermediates rather than end products [11]. $16 \mathrm{~K}$ fragment is cleaved to several lower molecular weight forms including $\gamma$-MSH-related peptides, while essentially all the ACTH is cleaved to yield $\alpha$-melanotropin ( $\alpha$-MSH) and CLIP (corticotropin-like intermediate lobe peptide) as end products. Likewise essentially all the $\beta$-LPH is cleaved 


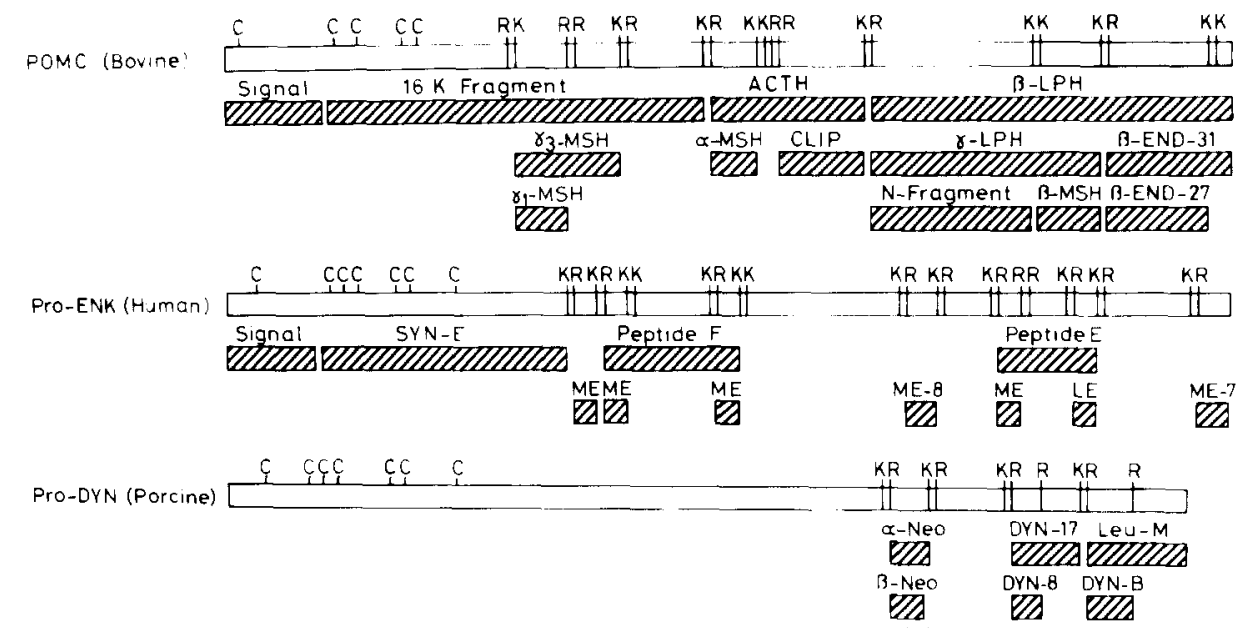

FIG. 1. Opioid Peptide Families. Abbreviations: POMC, pro-opiomelanocortin; ACTH, adrenocorticotropin; $\beta$-LPH, beta lipotropin; $\gamma$-MSH, gamma-melanocortin; $\alpha$-MSH, alpha melanotropin; CLIP, corticotropin-like intermediate lobe peptide; $\gamma$-LPH, gamma lipotropin: $\beta$-End-31, beta-endorphin( 1 31): N-Frag, $\mathrm{NH}_{2}$-terminal fragment of $\gamma$-LPH; $\beta$-MSH, beta-melanotropin: $\beta$-END-27, betaendorphin(1-27); Pro-Enk, pro-enkephalin; Syn-E, synenkephalin: ME. [Met]enkephalin; ME-8, [Met]enkephalin-Arg-Gly-Leu; ME-7. [Met]enkephalin-Arg-Phe: LE, [Leu]enkephalin: Peptide F. Pro-enk (107-140); Peptide E, Pro-enk(210-235); Pro-Dyn, pro-dynorphin: $\alpha$-Neo, alpha-neoendorphin; $\beta$-Neo, beta-neo-endorphin: Dyn A-17, dynorphin A(1-17); Dyn A-8, dynorphin A(1-8); Leu-M, leu-morphin: Dyn B, pro-dyn(228-240); C, cysteine; K, lysine: R. arginine. The scale is $1 \mathrm{~cm}$ equals five amino acids. Modified after Mains $c^{\prime} t$ al. 158].

to yield $\beta$-LPH-related peptides and $\beta$-endorphin-sized material as end products. Following the proteolytic cleavage of $\beta$-endorphin from $\beta$-LPH, $\beta$-endorphin is further posttranslationally modified by a combination of $\mathrm{COOH}$-terminal proteolytic cleavage and $\alpha, \mathrm{N}$-acetylation to yield opiate inactive $\alpha, \mathrm{N}$-acetyl- $\beta$-endorphin( 1-27) and $\alpha, \mathrm{N}$-acetyl$\beta$-endorphin(1-26) as the major end products $[19,38,57]$.

Processing of POMC in the arcuate nucleus appears to resemble the processing pattern in the intermediate pituitary in that the principal end products are $\alpha$-MSH-sized and $\beta$-endorphin-sized forms [35]. One significant difference between these two regions, however, is that the level of acetylation of $\alpha$-MSH- and $\beta$-endorphin-related material is much lower in the arcuate nucleus than in the intermediate pituitary $[20,55]$. In the terminal fields of the POMC-arcuate system, the levels of acetylated $\beta$-endorphin-sized material increase, but never approach the level of acetylation seen in the intermediate pituitary [2]. Little is known about the processing of POMC in the nucleus tractus solitarius; however, analyses of extracts of brainstem indicate that $\beta$-endorphin-sized material is primarily $\mathrm{COOH}$-terminally truncated and $\alpha, \mathrm{N}$-acetylated [56].

\section{THE PRO-ENKEPHALIN SYSTEM}

End products of the pro-enkephalin (pro-enk) precursor are found in the adrenal medulla and are distributed widely in the central nervous system [41]. Figure 2 contains a list of pro-enk cell bodies found in brain. Because of the vast, complicated distribution of the pro-enk system in the brain, it has been very difficult to establish cell body-terminal field relationships. In addition, little progress has been made in understanding the steps involved in the post-translational processing of pro-enk in either the adrenal medulla or brain. What is clear is that this precursor yields four copies of [Met]enkephalin, one copy of [Leu]enkephalin and at least two [Met]enkephalin extended peptides as end products [25]. In addition, a number of studies indicate that larger forms, containing more than one enkephalin sequence, may also serve as end products [34].

\section{THE PRO-DYNORPHIN SYSTEM}

End products of the pro-dynorphin (pro-dyn) system also enjoy a wide distribution in the central nervous system, and like the pro-enk system, there are several pro-dyn cell body regions in the brain (Fig. 2) [30]. Although there are regions in the brain where the pro-enk and the pro-dyn systems overlap, anatomical studies using several antisera directed against regions of either pro-dyn or pro-enk have demonstrated that these two systems are anatomically distinct [53]. Furthermore, these studies suggest that pro-dyn is not a major source of [Leu]enkephalin in brain. The steps in the post-translational processing of pro-dyn have not been determined, however, the following end products have been identified: $\alpha-$, and $\beta$-neo-endorphin, dynorphin $A(1-17)$, dynorphin A(1-8), leumorphin, and dynorphin B (Fig. 1) [21. $23,27.33,48]$. Recent studies on the ratio of dynorphin $A(1-17)$ and dynorphin $A(1-8)$ in different regions of the brain suggest that pro-dyn may undergo differential posttranslational proteolytic processing [54].

\section{POTENTIAL REGULATORY SITES}

Given our present level of understanding of the three opioid systems, it appears that pituitary-POMC may be the best model for investigating different strategies of regulation. In a typical secretory cell, the synthesis and release of a polypeptide is via a cascade sequence which begins with transcription, proceeds through translation and posttranslational processing and concludes with secretion. In the nucleus, transcription of a specific gene results in the synthesis of specific hn RNA (heterologous RNA). Studies on 


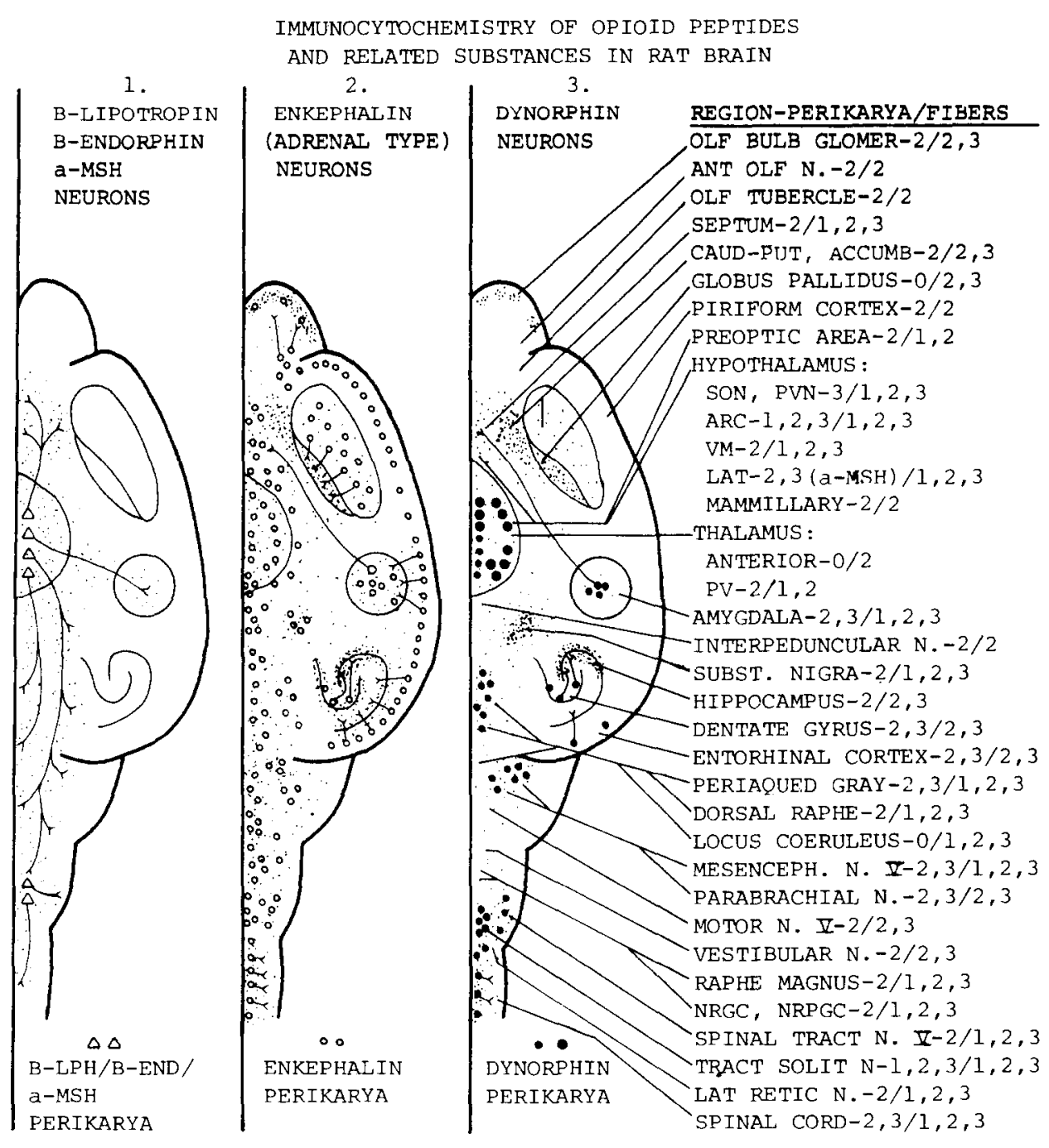

FIG. 2. Anatomical distribution of endorphins in the brain. These schematic horizontal drawings show the distribution of POMC (panel 1), pro-enkephalin (panel 2) and pro-dynorphin (panel 3) neurons in the rat brain. To the right is a list of brain regions where perikarya/fibers of each system are found. Each system is designated by its respective number (e.g., 2/2,3:enkephalin perikarya/enkephalin and dynorphin fibers). Note also that each line pointing to a specific structure to panel 3 also designates the same structure in panels 1 and 2 . The larger dynorphin perikarya represent the hypothalamic magnocellular neurons.

several eucaryotic gene systems indicate that hnRNA is post-transcriptionally processed (i.e., removal of introns, proper arrangement of exons, $3^{\prime}$ polyadenylation) to yield mature mRNA [13]. In the cytoplasm, mRNA containing the code for polypeptides destined for secretion are translated on the rough endoplasmic reticulum. During translation important processing events occur including the insertion of the signal peptide region of the nascent polypeptide through the bilayer of the endoplasmic reticulum, eventual removal of the signal peptide, and co-translational modifications such as glycosylation and phosphorylation. Following the termination of translation, the newly synthesized polypeptide passes through the endoplasmic reticulum and Golgi to the secretory granule. At this time a series of post-translational events may occur including proteolytic cleavage and enzymatic modification (i.e., acetylation, amidation and sulfation). During storage and secretion, the availability of different pools of granules for release may represent yet another level of regulation. Finally following release, selectivity at the receptor may provide another area for fine tuning.

In the following sections each of these potential regulatory sites will be considered using the POMC-pituitary system as a model. Where appropriate, examples will be presented for opioid systems in the brain. Finally, studies on other peptidergic systems that may serve as models for understanding opioid peptide regulation will be cited. Where appropriate the value of multiple strategies will be emphasized.

\section{Transcription}

Stimuli which either positively or negatively affect transcription will ultimately influence the amount of precursor synthesized. A paradigm which has been used on the 
POMC-anterior pituitary system to measure changes in transcription is adrenalectomy. The hypothalamus-anterior pituitary-adrenal axis maintains the steady state levels of glucocorticoids in plasma. Removal of the adrenals results in a rapid decline in plasma glucocorticoids which is accompanied by an increase in the secretion and synthesis of POMC end products in corticotrophs. Two approaches which have been used to measure changes in transcription in this paradigm are: (1) measurement of de nov synthesis of hn RNA; (2) changes in the level of POMC mRNA.

The de novo synthesis of hnRNA in anterior pituitary has been measured by the in vitro nuclear transcription assay [9] and POMC-specific complementary DNA (cDNA) probes. In this procedure nuclei, isolated from anterior pituitary cells following adrenalectomy, are incubated in medium containing radiolabeled nucleotides and the level of total radiolabeled hnRNA is measured by scintillation counting and compared to POMC specific hnRNA. Using this procedure a several fold increase in POMC hnRNA was observed in nuclei isolated from adrenalectomized animals as compared to control animals [9]. Beyond a simple increase in POMC hnRNA synthesis, it is not apparent whether adrenalectomy has any effect on the rate or nature of posttranscriptional processing of POMC hn RNA. This point is particularly relevant since studies on the synthesis of calcitonin mRNA indicate that post-transcriptional processing, that is the rearrangement of exons in the final mRNA transcript, can change as a function of the time in culture [7]. Thus the importance of the information gained from nuclear transcription assays is considerably enhanced when taken in conjunction with assays that quantify the amount of mature mRNA in a cell. This approach has been used for the anterior pituitary/adrenalectomy paradigm. Birnberg et al. [9] not only measured nuclear transcription rates in the anterior pituitary, but also quantified changes in the levels of POMC mRNA as a result of adrenalectomy by solution hybridization to a POMC-specific cDNA probe. This procedure demonstrated a 15-20 fold increase in POMC mRNA in anterior pituitary 18 days after adrenalectomy. Thus taken together these two procedures indicate that adrenalectomy induces an increase in POMC mRNA synthesis in corticotrophs.

Quantitation of mRNA levels with specific complementary DNA probes has also been applied to other opioid systems as well. For example, the POMC-intermediate pituitary system is regulated by tonic inhibition via a dopaminergic pathway [10]. Daily intraperitoneal injections of the dopamine antagonist haloperidol results in an increase in the release and synthesis of POMC end products in melanotrophs. Chen et al. $[10]$ have observed a 3 to 5 fold increase in POMC mRNA levels in the intermediate pituitary, as measured by hybridization to a specific POMC complimentary DNA on nitrocellulose filters (Dot Blot Procedure), as a result of haloperidol treatment. Extending these approaches to brain, Tang et al. [50] have observed a four fold increase in pro-enk mRNA levels, as measured by solution hybridization, accompanied by a two fold increase in [Met]enkephalin levels in the striatum following haloperidol treatment. The success of these experiments indicate that the hybridization procedures for measuring mRNA will be useful in monitoring the regulation of transcription in other brain regions.

\section{Translation}

The procedures outlined in the preceding section provide information on changes in the level of mRNA transcript, but do not indicate whether elevated levels of mRNA transcript necessarily result in increased synthesis of translation products (i.e., POMC, Pro-enk, Pro-dyn). In this section, examples will be presented to show that changes in the rate of translation or in the rate of co-translational processing are useful indicators of the activity of a cell.

In the case of pituitary tissue, quantitation of newly synthesized translation product can be done via an in vitro pulse radiolabeling paradigm. Pituitary tissue is well suited for this sort of analysis since either enzy matically dispersed pituitary cell suspensions or monolayer cultures of enzymatically dispersed pituitary cells are viable in culture for extended periods [39,42]. Utilizing this approach, Shiomi and Akil [49] have assessed the effect of acute stress on the rate of synthesis of POMC. Since acute stress is known to induce the coordinate release of $\mathrm{ACTH}$ and $\beta$-endorphin from the anterior pituitary, the question was asked whether this paradigm had any effect on the rate of synthesis and posttranslational processing of POMC. Pulse labeling of anterior pituitary cells obtained from rats following acute stress revealed a $128 \%$ increase in immunoprecipitable POMC-sized material as determined by SDS PAGE analysis. Furthermore, pulse/chase studies indicated a significant decrease in the half life of POMC from $35 \mathrm{~min}$ in control animals to 18 min in treated animals following acute stress. Thus the acute stress paradigm not only affects the level of synthesis of POMC in the anterior pituitary, but also the rate of posttranslational processing.

Changes in the kinetics of a cell may also be reflected by changes in the rate of co-translational processing. While the cleavage of signal or leader sequence is co-translational, it has a measurable half-life in the case of POMC, on the order of a few minutes (Akil ' $t$ al., unpublished data). It is therefore theoretically possible to measure the pre-prohormone (i.e., POMC with signal sequence attached), even though it constitutes a very small proportion of total POMC. We have developed and validated an antiserum specific to POMCsignal sequence [3]. Using this antiserum, we have shown that during periods of enhanced release and biosynthesis, there is a relative increase in immunoreactive pre-POMC. For example, following acute stress which results in $25 \%$ depletion of pituitary $\beta$-endorphin and ACTH, there is a period of increased biosynthesis as indicated by the pulse chase study described above. and by the restoration of total ACTH/ $\beta$-endorphin content in the lobe two hours poststress. During those two hours, the amount of measurable pre-POMC, and its ratios to total $\beta$-endorphin is significantly increased (Akil et al., in preparation).

This approach can also be used to measure specifically the rate of conversion of pre-prohormone to prohormone using pulse labeling paradigms in primary pituitary cultures and specific immunoaffinity columns built with anti-POMC signal and anti- $\beta$-endorphin antisera. Here again, activation of release (haloperidol-induced in the intermediate lobe) also leads to increased incorporation into pre-POMC (increased signal immunoreactivity at the end of the pulse period relative to control cultures) and increased rate of conversion from the pre-pro to the proforms (Akil ct al., in preparation). It therefore appears that both translational and cotranslational events can be controlled by changes in demand; in this case changes in release and content of POMC products.

Both of the procedures outlined above have relied, at least in part, on in vitro radiolabeling procedures as a method 
for identifying newly synthesized precursor protein. While this approach is very applicable for pituitary tissue, culturing of dispersed neurons is a far more difficult task. To begin with, adult CNS neurons are particularly difficult to maintain in culture. Although fetal and neonatal CNS tissue have greater viability in culture, studies in several laboratories, including our own $[5,32]$, indicate that processing of POMC in fetal and neonatal pituitary differs from POMC processing in adult tissue. Similar developmental differences may also apply to neuronal opioid peptide systems. Based on these observations, it may be more appropriate to attempt in vivo labeling of brain tissue. This approach has been successfully used to elaborate the biosynthesis of oxytocin and vasopressin in the magnocellular-posterior pituitary system |47|. Although in vivo labeling will be more difficult for the opioid peptide systems due to the low density of opioid peptide neurons, this procedure may be the best approach for studying the kinetics of opioid peptide biosynthesis in the brain. However, for the present. a considerable amount of information can be inferred about the biosynthesis of opioid peptides from biochemical characterization of the steady state products of these systems. In particular variations in the multiple molecular weight forms of these products can serve as indicators of differential regulation.

\section{Post-Translational Processing}

Following translation, precursors of low molecular weight polypeptides undergo a series of post-translational modifications which include proteolytic cleavage of the precursor and biosynthetic intermediates, and enzymatic modification of the end products. Knowledge of the steps in the biosynthetic pathway coupled with complete characterization of the end products not only provides information on the function of the secretory cell, but also may indicate potential regulatory sites in the system.

In the POMC-pituitary system, differences in proteolytic processing of POMC in anterior and intermediate pituitary are clearly reflected in the differential biological activities of the end products of these regions $[4,5]$. ACTH is one of the major end products of the anterior pituitary and accordingly corticotropic cells regulate glucocorticoid synthesis and release in the adrenal cortex [8]. By contrast, in the intermediate pituitary, ACTH is cleaved to $\alpha$-MSH and CLIP. While $\alpha$-MSH has little, if any, effect on adrenal function in adults, this polypeptide is a potent stimulator of physiological color change in several species of non-mammalian vertebrates [8]. In a similar manner, the proteolytic processing of $\beta-\mathrm{LPH}$ in the pituitary of mammals is also region specific. In the anterior pituitary the end products are roughly equal amounts of $\beta$-LPH, $\gamma$-LPH, and opiate active $\beta$-endorphin [18], while in the intermediate pituitary the end products are $\gamma$-LPH-related forms and opiate inactive forms of $\beta$-endorphin [11]. Although the function of $\beta$-LPH-related end products in the periphery is still unclear, it is intriguing to propose that differences in $\beta$-LPH post-translational processing, like ACTH post-translational processing, are also related to the distinct functions of corticotrophs and melanotrophs. Furthermore, shifts in processing patterns in a specific region may also be related to differences in function. For example, while the molar ratio of $\beta$-LPH to $\beta$-endoprhin in the mouse anterior pituitary is $2: 1$ [24], analysis of extracts of the anterior pituitary of the rhesus monkey (Akil et al., unpublished data) reveal a molar ratio of $\beta$-LPH to $\beta$-endorphin of 1:2. Differences in the degree of post-translational processing of $\beta$-LPH are even more pronounced as one moves down the phylogenetic tree. In the anterior pituitary of the reptile, Anolis carolinensis, the molar ratio of $\beta$-LPH to $\beta$-endorphin is $1: 40$ and resembles the ratio seen in the intermediate pituitary of this species and the intermediate pituitaries of mammals [16]. These changes in proteolytic processing may indicate that the corticotrophs have species specific functions.

Evidence of differential proteolytic post-translational processing is also seen in the pro-dyn system. Weber ' $t$ al. [54] have reported that the molar ratio of dynorphin(1-17) to dynorphin( $1-8)$ varies in different regions of the brain. In support of these observations, we have looked at just two terminal field regions in the pro-dyn system, the posterior pituitary and the substantia nigra, and found that the molar ratio of dynorphin(1-17) to dynorphin(1-8) in the former terminal field is $1: 2$ while in the latter terminal field the ratio is $1: 35$ [17].

In addition to examples of differential proteolytic processing, there are also examples of differential enzymatic modification of end products in the POMC-pituitary system. For example, although both the anterior and intermediate pituitary of the rat synthesize $\beta$-endorphin-size material [9], anterior pituitary $\beta$-endorphin is opiate active, while approximately $90 \%$ of the $\beta$-endorphin-sized material in the intermediate pituitary is $\alpha, \mathrm{N}$-acetylated $[19,39,57]$ and hence lacks opiate activity [1]. Accordingly, approximately $90 \%$ of the $\alpha$-MSH-sized material in the rat intermediate pituitary is $\alpha, \mathrm{N}$-acetylated, however, in the case of $\alpha$-MSH, $\alpha$, $\mathrm{N}$-acetylation increases the potency of this polypeptide in physiological color change bioassay systems [46]. The detailed steps in the biosynthetic pathway for the acetylation of $\beta$-endorphin- and $\alpha$-MSH-sized peptides in the rat intermediate pituitary are presented in Fig. 3. Based on this pathway, it has been proposed that acetylation may serve as a mechanism for selectively activating one end product while inactivating another end product [55]. While this strategy appears appropriate for describing the activities of end products in the rat intermediate pituitary, a review across species indicates that other cellular strategies occur (Table 1). For example, in the salmon pituitary all the $\beta$-endorphin is $\alpha$, $\mathrm{N}$-acetylated; however, the major form of $\alpha$-MSH-sized material is ACTH(1-13) $\mathrm{NH}_{2}$ [28,29]. Furthermore, in the reptile intermediate pituitary only non-acetylated forms of $\beta$-endorphin are synthesized [15]. These observations indicate that one level of regulation resides in the substrate specificity of the post-translational processing enzymes. Yet substrate specificity may represent just one level of control. There is increasing evidence that in the intermediate pituitary of the toad, Xenopus laevis, the acetylation of ACTH(1-13) $\mathrm{NH}_{2}$ to $\alpha$-MSH ( $\alpha, \mathrm{N}$-acetyl [ACTH(1-13) $\mathrm{NH}_{2}$ ] occurs at secretion [40]. Thus, in this system the enzymatic modification of $\mathrm{ACTH}(1-13) \mathrm{NH}_{2}$, is directly tied to physiological demand. These examples point out that the synthesis and activation of the post-translational processing enzymes represents yet another set of strategies used by the peptidergic cell for regulating its functional capabilities.

\section{Secretion}

Since it is now apparent that any given precursor can yield multiple products which vary in specificity and biological activity, it becomes critical to determine which products are released, and under which circumstances. In some instances the complexities of the processing and the post- 
TABLE 1

ACEYLATION OF $\beta$-ENDORPHIN AND $\alpha$ MSH

\begin{tabular}{|c|c|c|c|c|}
\hline Species & Tissue & $\beta$-Endorphin & $\alpha \mathrm{MSH}$ & References \\
\hline Rat & Intermediate Pituitary & $90 \%$ Acetylated & $90 \%$ Acetylated & $\begin{array}{c}{[19,20,2]} \\
35,57]\end{array}$ \\
\hline Salmon* & Pituitary & All Acetylated & Major Form: ACTH(1-13) $\mathrm{NH}_{2}$ & $|28.29|$ \\
\hline Reptile ${ }^{\dagger}$ & Intermediate Pituitary & All Non-Acetylated & Not Determined & {$[17]$} \\
\hline Amphibian: & Intermediate Pituitary & Not Determined & $\begin{array}{l}\text { Acetylation of ACTH(1-13) } \mathrm{NH}_{2} \\
\text { Occurs at Secretion }\end{array}$ & [40] \\
\hline
\end{tabular}

* Oncorhynchus ke'ta.

tAnolis carolinensis.

¿xenopus laciois.

translational modifications are such that it is difficult to determine which is the main product. For example, in the case of the neuro-intermediate lobe, should we conceive of the opioid active $\beta$-endorphin(1-31) as the main product, with the $\mathrm{N}$-acetylated forms as metabolites? Or is the last peptide generated by the pathway, e.g. $\alpha$. N-acetyl$\beta$-endorphin(1-26), the one which is differentially released? Is it conceivable that under different conditions of demand, the system would utilize different peptides with different potencies or dissimilar physiological effects? These are obviously questions which are key to our understanding the physiology of the system and its regulation. Unfortunately, there is little hard evidence on this subject and a good number of preconceptions. For example, it is easy to assume that "more pharmacologically potent is better," which would lead us to construe $\beta$-endorphin(1-27) or $\beta$-endorphin(1-26) as metabolites. However, one can certainly conceive of conditions where the release of an extremely potent or long acting opioid at a given synapse is not necessary or even desirable, and where the delivery of a less extreme message is ideal. Alternatively, in conditions of high demand, the longer acting, more potent agent may be required. It is also easy to think primarily in terms of one main function, e.g., activity of the opioid peptides at the opioid receptors, which would lead us to the conception that the $\mathrm{N}$-acetylated forms are totally inactive. However, it is now well known that peptides carry more than one message of biological activity, and several non-opioid effects of the opioid peptides have indeed been demonstrated [14,52].

Given that we have no a priori way of determining the pattern of release or its biological regulation, we need to develop models for studying these questions. The use of potassium-stimulated release is fraught with difficulties, since this method does not discriminate between various releasable pools. What is required is the systematic study of multiple forms released under well-defined conditions of high or low demand in order to understand the activation of a particular system. These conditions can be induced pharmacologically or physiologically by altering the animal's environment. An example of a viable pharmacological model is the activation of release from adrenal medulla via cholinergic agents [46,51]. This model has been useful in demonstrating that the enkephalins are co-released with the catecholamines, and that several opioid peptides are liberated. These include [Met]- and [Leu]enkephalin, [Met]-enkephalinArg-Gly-Leu and [Met]-enkephalin-Arg-Phe. However, the releasability of these compounds relative to the longer more

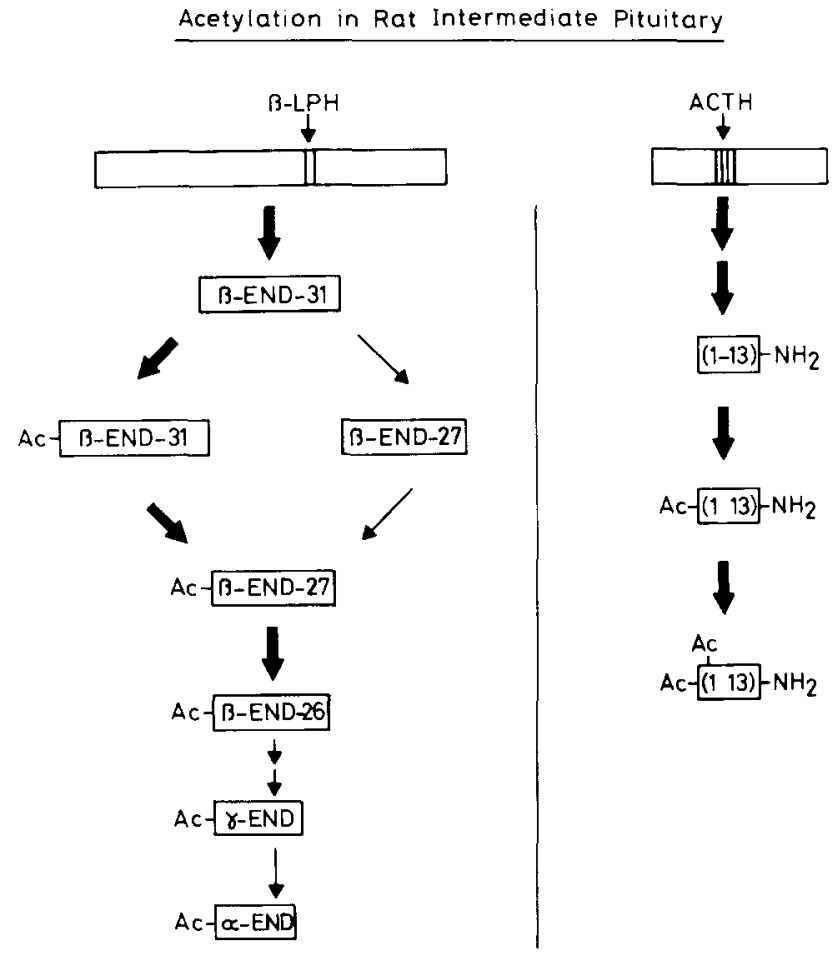

FIG. 3. Schematic of the acetylation of $\beta$-endorphin and $\alpha$-MSH in rat intermediate pituitary. The wide arrows indicate major biosynthetic pathways, whereas the narrow arrows indicate minor pathways. The steps in the biosynthetic pathway between $\beta$-endorphin(1-26) and $\gamma$-endorphin. and the steps in the pathway between $\mathrm{ACTH}$ and $\mathrm{ACTH}(\mathrm{I}-13) \mathrm{NH}_{2}$ are not known and these parts of the respective biosynthetic pathways are represented by two arrows in succession. See Mains 't al. [58].

stable pro-enkephalin products, such as peptides $E$ or $F$, has not been systematically examined.

Even the better studied POMC system has not been well investigated with regard to differential release of multiple forms. Herbert and his co-workers $[6]$ have used an anterior lobe primary culture model system, and shown that a medium containing endogenous releasing factor(s) differentially liberates the smaller, more completely processed POMC products, such as $\beta$-endorphin, rather than the pre- 
cursors or biosynthetic intermediates. In our own laboratory, we have been addressing this issue by studying the effect of stress on release of multiple forms of $\beta$-endorphin from the neuro-intermediate lobe and from the midbrain of the rat (Akil et al., in preparation). Our results to date suggest that, in this model, the most processed forms are released preferentially. This means that, in the case of midbrain, $\beta$-endorphin( $1-27)$ or $\beta$-endorphin( $1-26)$ are released in preference to the ten-fold more potent $\beta$-endorphin(1-31). When the brain POMC system is challenged, then allowed to recover over 24 hours, the shorter forms accumulate, and are released again upon further stress. This does not mean that $\beta$-endorphin( $1-31)$ is not released at all or that the shorter forms are exclusively liberated. It simply means that the ratios of forms seen in terms of content do not predict the ratios of released peptides. This might suggest that the most modified, last product of the biosynthetic pathway is, indeed, the "true product" of the system. However, this is a hasty conclusion. We still do not know what happens when the demand on the system is sustained and little time is available for full recovery and complete processing. It is conceivable that the POMC system in brain liberates the less potent material as a matter of course, but that continued demand on the system would lead to the exocytosis of the pool which contains the more opiate-active $\beta$-endorphin(1-31). This may impart a great deal of flexibility to the system, allowing it to respond to various levels of demand by delivering opioids of varying and appropriate potencies. Such a hypothesis requires systematic testing under a number of physiological and pharmacological challenges, and with different time courses of recovery. It does, however, illustrate the possible richness of these multi-product systems, and the complexities in their regulation.

The regulation of release of endogenous opioids may involve another level of control, beyond the issue of different releasable pools. It appears that the overall "releasability" of these peptides could be altered by physiological or environmental events. A series of experiments was conducted in our laboratory concerning possible alterations of releasability of POMC products from anterior lobes of rats which had undergone various treatments (Young et al., in preparation). Primary culture of the anterior lobes of rats which had been subjected to acute stress, repeated daily stress, or no stress, were compared in terms of releasability of $\beta$-endorphin and ACTH by the secretagogues CRF and vasopressin. These studies suggested that the repeated activation of the anterior lobe corticotrophs with 25 minutes of daily stress (intermittent footshock) for two weeks, leads to enhanced releasability of POMC products. The animals with a history of repeated daily stress exhibited greater proportional release of $\beta$-endorphin and ACTH to a given dose of CRF, vasopressin or their combination. Furthermore, CRFinduced release in these animals was less inhibited by the presence of corticosteroids.

It therefore appears that the POMC system can be regulated both in terms of which products are released, and the ease with which the release does take place. The exact mechanisms of these controls remain to be elucidated. It is apparent, however, that the plasticity of these systems is remarkable, and that this level of control and regulation may be critical for integrated function. We are clearly in need of understanding the principles of such regulation, and determining whether these principles are unique to a given system (e.g., endocrine versus neuronal, POMC versus proenkephalin), or whether they have a wide heuristic value
Receptors

Throughout the above discussion, we have focused on the issues concerning control of peptide biogenesis and release, but have said nothing of receptors. This is clearly only one side of the equation. The receiving end of these systems, be it postsynaptic receptors, or endocrine target organs, can exhibit a great deal of selectivity and propensity for regulatory controls. A complete discussion of the issues of receptor types and regulation is beyond the scope of this paper. We shall briefly outline the general features of opioid receptors and point to the major theoretical questions in this area.

The multiplicity of endogenous opioid peptides is matched by a multiplicity of opioid receptors. The three receptor types which have been best described are the mu receptor, which interacts with morphine-like substances, the delta receptor which is selective for enkephalin-like substances, and the kappa receptor, which is selective for alkaloids of the type of ketocyclazocine, and for dynorphin and neo-endorphin. It is thought that the activation of a particular receptor subtype may result in a unique pharmacological profile. Indeed, careful pharmacological characterizations, both in vive and in vitro. first led Martin and coworkers and Kosterlitz and coworkers [22,37] to put forth the concept of multiple receptor types. There are a few distinctive characteristics of the activations of specific opioid receptors, such as the production of analgesia when mu receptors in relevant circuits are activated. However, the specific physiological roles of each receptor subtype are far from clear. Furthermore, the relationship between a particular family of opioids and a particular opioid receptor type is not well established. There is a tendency to associate the delta receptor with the pro-enkephalin family, and the kappa receptor with the pro-dynorphin family, based on the preference of the peptide products for these receptor subtypes. However, each precursor produces multiple products with a range of selectivity. For example, while [Leu]enkephalin is clearly delta selective, [Met]enkephalin is less so, and other products of pro-enkephalin can be reasonably potent at the mu receptor. Similarly, the pro-dynorphin products, while clearly kappa selective, also exhibit a range of specificities. Further, $\beta$-endorphin, which derives from the third opioid cannot be construed as the endogenous mu ligand. Rather, it appears almost equipotent at the mu and delta sites, and has been postulated to have its own binding site (Epsilon). In other words, there is no obvious opioid family associated with the best characterized opioid receptor, the mu sites. Instead, autoradiographic studies, when coupled with immunohistochemistry, reveal the association of mu receptors with all three endogenous opioid families [36]. Thus, each family appears to produce multiple opioid products, capable of interacting with multiple opioid receptors, and more than one receptor type appears present in the vicinity of the terminals. The fine local circuitry may be more specialized, and may yield selectivity which is hard for us to discern with current techniques. However, it is evident at this stage that a simplistic model of one opioid-family: one opioid receptor type can not be upheld. Finally, the relations between opioids as hormones in the periphery and any specific receptor type is totally obscure, since there are few well characterized peripheral opioid endocrine functions, in spite of the abundance of opioid peptides in endocrine glands.

Most likely, the multiple opioid receptors are subject to a dizzying number of regulatory processes, ranging from control of their affinity, to their relative numbers, their coupling 
to second messenger systems, their possible interactions amongst each other, or with other membrane components. We should also bear in mind that each peptide can carry multiple messages, including non-opioid ones [52], and that the opioids are co-released with other potent peptides such as $\mathrm{ACTH}$, with which they may interact [4]. It is therefore apparent that a great deal of the burden of control lies not only in the releasing end, but in the receiving end. The fine tuning of the system is likely to result from the interface of these two main components, and the possibility of feedback between them.

In conclusion, it is becoming clear that one can study the biosynthetic and release actions of neuropeptide producing cells at a variety of levels. Rather than conclude that there is one key "rate controlling" step which will reflect the activity of the system. we are more impressed with changes under demand throughout the biosynthetic chain. In other words each level from the gene through precursor synthesis to release is significantly influenced by demand. The task for the future is the development of new tools for studying neuropeptide turnover and the careful application of these classical cell biological tools to the neuron.

\section{ACKNOWLEDGEMENTS}

We wish to thank Marcia Ritchie. Guilio Baldrighi, and Sharon Burke for their assistance in the preparation of this manuscript. In addition we wish to express our appreciation to Dr. Henry Khachaturian for supplying us with Fig. 2, and Dr. Michael Lewis for his helpful comments. This work was supported by NIDA Center grant DA00154, NIDA grant DA02265 and the Theophile Raphael Grant from the University of Michigan.

\section{REFERENCES}

1. Akil, H., E. Young, S. J. Watson and D. H. Coy. Opiate binding properties of naturally occurring $\mathrm{N}$ - and $\mathrm{C}$-terminus modified beta-endorphin. Peptides 2: 289-292, 1981 .

2. Akil, H. and S. J. Watson. Beta-endorphin and biosynthetically related peptides in the CNS. In: Handbooh of Psychopharmacology, vol 16, edited by L. Iversen, S. D. Iversen and S. H Snyder. New York: Plenum Publishing Corp., 1982. pp. 209 253

3. Akil, H., H. Shiomi, R. Thompson, S. Lax, D. Coy and S Watson. The signal peptide of pro-opiomelanocortin: Validation of a specific radioimmunoassay. Lif $c^{\prime} S_{c} i$ 31: 2271-2273, 1982.

4. Akil, H., S. J. Watson, E. Young, M. E. Lewis, H. Khachaturian and J. M. Walker. Endogenous opioids: Biology and Function. In: Annual Revie'w of Neuroscience. Palo Alto: Annual Reviews Inc., in press.

5. Alessi, N. E., H. Khachaturian, S. J. Watson and H. Akil. Postnatal development of beta-endorphin immunoreactivity in pituitary. Life $S_{c i}$ 33: 57-61, 1983.

6. Allen, R. G., M. Hinman and E. Herbert. Forms of corticotropin and beta-endorphin released by partially purified CRF in mouse anterior pituitary cultures. Newropeptide's 2: 175-184. 1982.

7. Amara, S. G., V. Jonas, M. G. Rosenfeld, E. S. Ong and R. M. Evans. Alternative RNA processing in calcitonin gene expression generates mRNAs encoding different polypeptide products. Nature 298: 240-244, 1982

8. Baker, B. The evolution of ACTH, MSH and LPH: Structure, function and development. In: Hormone Evolution, vol 2 , editor. E. J. W. Barrington. New York: Academic Press, 1980, pp. $643-722$.

9. Birnberg. N., J. C. Lissitzky, M. Hinman and E. Herbert. Glucocorticoids regulate pro-opiomelanocortin gene expression in viro at the levels of transcription and secretion. Proc Noil Acod Sci USA 80: 6982-6986, 1983.

10. Chen, C. L. C., F. T. Dionne and J. L. Roberts. Regulation of the pro-opiomelanocortin mRNA levels in rat pituitary by dopaminergic compounds. Proc Natl Acad Sci USA 80: 22112215,1983

11. Chretien, M. and N. G. Seidah. Chemistry and biosynthesis of pro-opiomelanocortin: ACTH, MSH's, endorphins and their related peptides. Mol Coll Endorrinol 21: 101-127, 1981

12. Costa, E., A. Guidotti, I. Hanbauer, T. Hexum, I. Saiani, S. Stein and H. Y. T. Yang. Regulation of acetylcholine receptors by endogenous co-transmitters: Studies of adrenal medulla. Fed Proc Fe'd Am Soc Exp Birl 40: 160-165, 1981.

13. Crick, F. Split genes and RNA splicing, Sicinc' 204: 264-271, 1979.

14. de Wied, G., G. L. Kovacs, B. Bohus, J. M. van Ree and H. M. Greven. Neuroleptic activity of the neuropeptide betaLPH(62-77) (|Des-Tyr ${ }^{1}$ lgamma-endorphin; DTgammaE). Eal I Phamacol 49: 427. 1978.
15. Dores, R. M. Evidence for multiple forms of beta-endorphinrelated substances in the pituitary of the reptile, Anolis caroline'nsis. Soc Newosci Abstr 11: 91, 1981.

16. Dores, R. M. Localization of multiple forms of ACTH- and beta-endorphin-related substances in the pituitary of the reptile, Anolis corolimensis. Peptides 3: 913-924, 1982.

17. Dores, R. M., H. Akil and S. J. Watson. Isolation of multiplesized immunoreactive forms of dynorphin-A in the substantia nigra. Sor Neurosci Absti 9: 586, 1983.

18. Eipper, B. A. and R. E. Mains. Structure and function of proadreno-corticotropin/endorphin and related peptides. Endoct Rev 1: 247-262, 1980.

19. Eipper, B. A. and R. E. Mains. Further analysis of posttranslational processing of beta-endorphin in rat intermediate pituitary. I Biol Che'm 256: 5689-5695, 1981 .

20. Evans, C. J., R. Lorenz, E. Weber and J. D. Barchas. Variants of alpha-melanocyte-stimulating hormone in rat brain and pituilary: Evidence that acetylated alpha-MSH exists only in the intermediate lobe of the pituitary. Biochem Biophys Res Commum 106: 910-919, 1982.

21. Fischli, W., A. Goldstein. M. W. Hunkapiller and L. E. Hood Isolation and amino acid sequence analysis of a 4,000-dalton dynorphin from porcine pituitary. Proc Natl Acad Sai USA 79: 5435-5437, 1982 .

22. Gilbert. P. E. and W. R. Martin. The effects of morphine and nalorphine-like drugs in the non-dependent chronic spinal dog. $J$ Pharmacol Exp Ther 198: 66-82, 1976.

23. Goldstein. A.. W. Fischli, L. I. Lowney, M. Hunkapiller and L. Hood. Porcine pituitary dynorphin: Complete amino acid sequence of the biologically active heptadecapeptide. Proc Nam Acrd Sci USA 78: 7219-7223, 1981.

24. Herbert, E. Discovery of pro-opiomelanocortin-a cellular polyprotein. Trends Biochem 6: 184-188, 1981.

25. Hollt, V. Multiple endogenous opioid peptides. Irends Neturosei 6: 24-26, 1983 .

26. Kakidani, H., Y. Furutani, H. Takehashi, M. Noda, Y. Morimoto, T. Hirose, M. A sai, S. Inayama, S. Nakanishi and S. Numa. Cloning and sequence analysis of cDNA for porcine heta-neo-endorphin/dynorphin precursor. Nature 298: 245-249. 1982.

27. Kanagawa, K., N. Minamino, N. Chino, S. Sakakibara and H. Matsuo. The complete amino acid sequence of alpha-neoendorphin. Biochem Biophys Re's Commun 99: 871-878, 1981.

28. Kawauchi, H. and K. Muramoto. Isolation and primary structure of melanotropins from salmon pituitary glands. Int $J P^{\prime} p t$ Protein Re's 14: 373-374, 1979.

29. Kawauchi, H., M. Tsubokawa, A. Kanezawa and H. Kitagawa. Occurrence of two different endorphins in the salmon pituitary Biochlom Biophys Res Commum 92: 1278-1288, 1980. 
30. Khachaturian, H., S. J. Watson, M. E. Lewis, D. Coy and A. Goldstein. Dynorphin immunocytochemistry in the rat central nervous system. Peptides 3: 941-954, 1982.

31. Khachaturian, H., M. E. Lewis, T. Kang and S. J. Watson. Beta-endorphin and related peptides. In: Handhook of Chemical Neurounatomy, vol 3, edited by T. Hokfelt and $\mathrm{A}$. Bjorklund. The Netherlands: Elsevier Biomedical Publishing, in press, 1983.

32. Khachaturian, H., N. Munfakh, N. E. Alessi and S. J. Watson Comparative ontogeny of three opioid systems in the rat CNS. Life Sci 33: 61-65, 1983 .

33. Kilpatrick, D. L., A. Wahlstrom, H. W. Lahm, R. Blaher and S. Udenfriend. Rimorphin, a unique, naturally occurring |Leulenkephalin-containing peptide found in association with dynorphin and alpha-neo-endorphin. Proc Nat Acad Sci USA 79: 6480-6483, 1982.

34. Kimura, S., R. V. Lewis, A. S. Stern, J. Rossier, S. Stein and S Udenfriend. Probable precursors of [Leu]enkephalin and [Met lenkephalin in adrenal medulla: Peptides of 3-5 kilodaltons. Proc Natl Acad Sci USA 77: 1681-1865, 1980.

35. Krieger, D. T., A. S. Liotta, M. J. Brownstein and E. A. Zimmerman. ACTH, beta-lipotropin, and related peptides in brain. pituitary, and blood. Re' Prog Horm Ress 36: 277-345, 1980

36. Lewis, M. E., H. Khachaturian and S. J. Watson. Comparative distribution of opiate receptors and three opioid peptide neuronal systems in rhesus monkey central nervous system. life Sci 33: 239-243, 1983.

37. Lord, J. A. H.. A. A. Waterfield, J. Hughes and H. W. Kosterlitz. Endogenous opioid peptides: Multiple agonists and receptors. Nature 267: 495-497, 1977.

38. Mains, R. E. and B. A. Eipper. Differences in the posttranslational processing of beta-endorphin in rat anterior and intermediate pituitary. I Biol Chem 256: 5683-5688, 1981.

39. Mains. R. E. and B. A. Eipper. Tissue culture of primary rat anterior pituitary cells. In: Regulatory Peptides: From Molecular Biology to Function, edited by E. Costa and M. Trabucchi. New York: Raven Press, 1982, pp. 1-8.

40. Martens, G. J. M., B. G. Jenks and A. P. van Overbeeke. $\mathrm{N}$-alpha-acetylation is linked to alpha-MSH release from pars intermedia of the amphibian pituitary gland. Nature 294: 558560.1981 .

41. Miller, R. J. The enkephalins. In: Handhook of Psychopharmacology, vol 16 , edited by $L$. Iversen, $S$. Iversen and $S$. $H$. Snyder. New York: Plenum Publishing Co., 1983, p. 109.

42. Mulder, G. H. and P. G. Smelik. A superfusion system technique for the study of the sites of action of glucocorticoids in the rat hypothalamus-pituitary-adrenal system in vitro. I. Pituitary cell superfusion. Endocrinology 100: 1143-1152, 1977.

43. O'Donohue, T. L. The opiomelanotropinergic neuronal and endocrine systems. Poptide's 3: 1039-1072. 1982
44. Nakanishi, S., A. Inoue, T. Kita, M. Nukamura, A. C. Y Chung, S. N. Cohen and S. Numa. Nucleotide sequence of cloned cDNA for bovine corticotropin-beta-lipotropin precursor. Nature 278: 423-427, 1979.

45. Noda, M., Y. Teranishi, H. Takahashi, M. Toyosato, M Notake, S. Nakanishi and S. Numa. Isolation and structural organization of the human pre- proenkephalin gene. Nattur' 297: 431-434, 1982.

46. Rudman, D., R. K. Chawla and B. M. Hollins. N, Odi-acetylserine ${ }_{1}$ alpha-melanocyte-stimulating hormone, a naturally occurring melanotropic peptide. J Biol Chem 254: 10102-10108, 1979

47. Russell, J. T., M. J. Brownstein and H. Gainer. Biosynthesis of neurohypophyseal polypeptides: The order of peptide components in pro-pressophysin and pro-oxyphsin. Neuropeptides 2 : $59-65,1981$.

48. Seizinger, B., V. Hollt and A. Herz. Evidence for the occurrence of the opioid octapeptide dynorphin(1-8) in the neurointermediate pituitary of rats. Biochem Biophys Res Commun 102: $197-205,1981$

49. Shiomi, $H$. and $H$. Akil. Pulse-chase studies of the POMC/beta-endorphin system in the pituitary of acutely and chronically stressed rats. Life $S_{c} i$ 31: 2271-2273, 1982.

50. Tang, C., E. Costa and J. P. Schwartz. Increase of proenkephalin mRNA and enkephalin content of rat striatum after daily injections of haloperidol for 2 to 3 weeks. Proc Natl Ac'ad Sci USA 80: 3841-3844, 1983.

51. Viveros, O. H., E. J. Diliberto, E. Hazum and K. J. Chang. Opiate-like materials in the adrenal medulla: Evidence for storage and secretion with catecholamines. Mol Pharmacol 16: $1101-1108,1979$

52. Walker, J. M., H. Moises, D. Coy, G. Baldrighi and H. Akil Non-opiate effects of dynorphin and des-tyr-dynorphin. Science 218: 1136-1138, 1982 .

53. Watson, S. J., H. Khachaturian, L. Taylor, W. Fishli, A. Goldstein and H. Akil. Pro-dynorphin peptides are found in the same neurons throughout rat brain: Immunocytochemical study. Proc Natl Acad Sci USA 80: 891-894, 1983.

54. Weber, E.. C. J. Evans and J. D. Barchas. Predominance of the amino-terminal octapeptide fragment of dynorphin in rat brain regions. Natlire 299: 77-79, 1982.

55. Zakarian, S. and D. Smyth. Distribution of active and inactive forms of endorphins in rat pituitary and brain. Proc Natl Acad Sci USA 76: 5972-5976, 1979

56. Zakarian, S. and D. Smyth. Beta-endorphin is processed differently in specific regions of rat pituitary and brain. Nature 296 $250-252,1982$

57. Zakarian, S. and D. G. Smyth. Review article: Distribution of beta-endorphin related peptides in rat pituitary and brain. Biochem IJ 202: 561-571, 1982.

\section{REFERENCE ADDED IN PROOF}

58. Mains, R. E., B. E. Eipper, C. C. Glembotski and R. M. Dores. Strategies for the biosynthesis of bioactive peptides. Tread Nelurosci 6: 229-235, 1983 . 